TILTAI, 2020, 1, 75-84 ISSN 1392-3137 (Print), ISSN 2351-6569 (Online)

\title{
ORGANIZACIJOS FIZINĖS APLINKOS REIKŠME் VADYBINIAMS PROCESAMS
}

\author{
Adomas Vincas Rakšnys, Deimantė Žilinskienė \\ Kazimiero Simonavičiaus universitetas, Vilniaus kolegija
}

\begin{abstract}
Anotacija
Straipsnyje nagrinejama fizinès organizacijos aplinkos - biuro įtaka įvairiems vadybos procesams. Pateikiama fizinès organizacijos aplinkos samprata, jos esminiai klasifikavimo būdai, nagrinèjami esminiai uždaro ir atviro biuro privalumai vidinès komunikacijos, konfliktų sprendimo, organizacinès kultūros ir subkultūrų puoselejjimo, darbuotojų produktyvumo ir kitų organizacinių reiškinių kontekste. XXI a. tendencijos atskleidžia, kad vis daugiau verslo organizacijų renkasi atviro biuro stilių, siekdamos atsiriboti nuo tradicinei biurokratinei organizacijai būdingos fizinès aplinkos. Straipsnio autoriai siekia kritiškai ịvertinti uždaro ir atviro biuro privalumus bei trūkumus, apžvelgti galimas ateities tendencijas ir organizacijų fizinès aplinkos tyrimų perspektyvas. Visgi šių kompleksinių veiksnių tyrimai pirmiausia numato tarpdisciplininę metodologinę prieigą, sutelkiant vadybos, ekonomikos, psichologijos, architektūros ir kitų sričių žinias, o Lietuvos moksliniame diskurse ši tema nesulaukia pakankamo dėmesio. Straipsnio autoriai siekia apibrèžti fizinės organizacijos aplinkos sampratą, nustatyti jos esminius bruožus, pateikti uždaros ir atviros fizinès aplinkos skirtumus. PAGRINDINIAI ŽODŽIAI: fizinè organizacijos aplinka, uždaras biuras, atviras biuras, vadyba, procesas.
\end{abstract}

\begin{abstract}
In the article, the importance of the physical environment of the organisation, the office, in achieving the efficiency of various management processes, is analysed. The article explains the concept of the physical environment of the organisation and its essential classification methods, and analyses the essential advantages of a closed and open office for internal communication, conflict resolution, organisational culture and subcultures, employee productivity, and other organisational phenomena. Twenty-first-century trends show that more and more business organisations are moving towards open office trends, in order to distance themselves from the physical environment of a traditional bureaucratic organisation. The authors of the article seek to critically evaluate the advantages and disadvantages of a closed and open office, and to review possible future trends and prospects for research into the physical environment of organisations. Nevertheless, research into these complex factors requires primarily an interdisciplinary methodological approach, combining a knowledge of management, economics, psychology, architecture, and other fields, and this topic does not receive sufficient attention in the Lithuanian scientific discourse. The authors of the article seek to define the concept of the physical environment of the organisation, identify its essential features, compare the differences between closed and open physical environments, and discuss possible perspectives for future research.
\end{abstract}

KEYWORDS: physical environment, closed office space, open office space, management, process.

DOI: http://dx.doi.org/10.15181/tbb.v84i1.2138 


\section{Ivadas}

Šiuolaikinių verslo, viešųų įstaigų ir nevyriausybinių organizacijų nuolat kintanti veiklos specifika, užduočių ir sprendžiamų problemų kompleksiškumas, procesų kaita lemia poreikị ieškoti naujų būdų, kaip didinti darbuotojų veiklos veiksmingumą. Darbuotojai vis dažniau skatinami igyti įvairių kompetencijų, turi gebèti dirbti globalizacijos, didelès rizikos ir žinių ekonomikos sąlygomis, taikyti modernias technologijas, skirtingus metodus, geriausius tarptautinius vadybos principus. Dideli reikalavimai keliami ne tik darbuotojams, bet ir organizacijoms: konkurencinè aplinka, geroji pasaulinè praktika, lyginimo metodo taikymas skatina organizacijas pirmiausia investuoti ị fizinès organizacijos aplinkos tobulinimą (Kaarlela-Tuomaala ir kt., 2009, p. 1424-1425). Ši tendencija būdinga ir Lietuvos organizacijoms, ypač verslo sektoriui. Moksliniame diskurse galima pastebėti ịvairių tyrimų, nagrinėjančių fizinès organizacijos aplinkos ir ịvairių darbuotojų veiklos aspektų sąsajas, jų galimą įtaką darbuotojų veiklos veiksmingumui. Naujausiuose tyrimuose S. Tuncer'is ir G. Licoppe (2018) plètoja diskusiją apie galimą organizacijų viduje ,,atvertų durų“ poveikį puoselèjant neformalią komunikaciją, ją skatinant. Diskutuojama apie fizinès aplinkos, ypač neformalių erdvių (rūkomụų̧, kavos gèrimo erdvių), galimą poveikị organizacinių subkultūrų, kurios gali mesti iššūkị dominuojančiai organizacinei hierarchijai ir kultūrai, atsiradimui (Peteri ir kt., 2020, p. 6).

J. Tomi's ir kt. (2015) Suomijoje atliko tyrimą, kurio metu stebėjo organizacinès kultūros ir darbuotojų kūrybiškumo veiksnių pokyčius kintant fizinei organizacijos aplinkai, t. y. pereinant nuo labiau biurokratinei organizacijai būdingos uždaros aplinkos prie atviresnio biuro laikraščio redakcijoje. Ch. Danielsson'as ir L. Bodin'as (2008) tyrinèjo, kaip organizacijos fizinè erdvè susijusi su pasitenkinimo darbu, sveikatos ir darbuotojų gerovès veiksniais. J. A. Veitch'as ir kt. (2008) ịrodè, kad biuruose naudojamo apšvietimo kokybẻ kelia darbuotojų produktyvumą ir gerina jų psichologinę būklę. Kita vertus, A. Brennan'o ir kt. (2002, p. 293) atlikto longitudinio tyrimo rezultatai atskleidè, kad atviras biuras gali mažinti pasitenkinimą darbu, didinti darbuotojų streso lygmenị ir net silpninti darbuotojų tarpusavio santykius.

Vertinant šių ir kitų tyrimų pagrindu suformuluotas išvadas galima daryti prielaidą, kad organizacijos fizinè aplinka pasižymi ịvairius vidinius organizacijos procesus skatinančia ar varžančia funkcijomis, todèl tinkamos darbo aplinkos kūrimas - būtina sąlyga, siekiant darbuotojų veiklos veiksmingumo (Elsbach, Pratt, 2007, p. 182; Danielsson, Bodin, 2008, p. 637). V. Peteri'o, ir kt. (2020, p. 2) teigimu, manipuliuojant organizacijos fizine erdve galima sukurti naujas valdymo 
formas, keisti esamus galios santykius, ittvirtinti kontrolès formas ar net suvienyti darbuotojus.

Visgi siekiant atlikti šių kompleksinių veiksnių tyrimus pirmiausia būtina tarpdisciplininė metodologinè prieiga, sutelkiant vadybos, ekonomikos, psichologijos, architektūros ir kitų sričių žinias, deja, Lietuvos moksliniame diskurse ši tema nesulaukia pakankamo dèmesio.

Straipsnyje keliama mokslinè problema: kaip fizinè aplinka gali veikti organizacijose vykstančius procesus.

Tikslas -išsiaiškinti fizinès aplinkos reikšmę organizacijų vadybos procesams. Straipsnyje siekiama apibrèžti fizinès organizacijos aplinkos sampratą ir esminius jos bruožus, palyginti uždaros ir atviros fizinès aplinkos skirtumus, aptarti galimas ateities tyrimų perspektyvas. Siekdami tikslo autoriai taikè mokslinès literatūros analizės, sintezès, ir apibendrinimo metodus. Tarptautinių tyrimų apžvalga autoriai siekia paskatinti mokslinę diskusiją ir empirinius šio reiškinio tyrimus Lietuvoje.

\section{Fizinė organizacijos aplinka, jos bruožai}

Šiame poskyryje aptarsime fizinès organizacijos aplinkos sampratą, išskirsime esminius jos bruožus, pateiksime pagrindinius klasifikavimo būdus. Moksliniame diskurse fizinė organizacijos aplinka paprastai skirstoma ị atvirą ir uždarą, t. y. privačią, tradicinę (Tomi ir kt., 2015; Kaarlela-Tuomaala ir kt., 2009; Brennan ir kt., 2002). Savo klasikinèje studijoje T. R. V. Davis'as (1984, p. 281) organizacijos fizinès aplinkos analizei pasiūlè tris elementus apimančią prieigą: fizinę struktūrą, fizini stimulą ir simbolistinius artefaktus. K. Elsbach'as ir M. G. Pratt'as (2007, p. 181-182), susisteminę ịvairių tyrejjų darbus, fizinę organizacijos aplinką apibūdino skirdami šiuos materialius elementus: organizacijos biuro dizainas, esami fiziniai barjerai - sienos, asmeninès darbuotojų zonos, ịranga, baldai ir jų išsidèstymas, apšvietimas bei kiti veiksniai. Kiti autoriai, pavyzdžiui, N. M. Ashkanasy'is ir kt. (2014, p. 1170) šią sampratą papildè tokiais fizinę aplinką veikiančiais veiksniais, kaip asmeninė darbuotojo erdvé, jos tankumas, galimybė darbo vietą personalizuoti ir susieti su savo tapatumu. Šią organizacijos biuro funkciją galima laikyti simbolistine, labiau pabrěžiant jos kultūrini turinị (Tomi ir kt., 2015, p. 392; Davis, 1984, p. 276-279). Pritariant autorių įžvalgoms galima teigti, kad esminiu bruožu, atskiriant tradicinị ir atvirą biurą vieną nuo kito, galima laikyti tai, kad darbuotojai atvirame biure dirba kartu (esant minimaliems barjerams arba jų nesant) (Brennan ir kt., 2002, p. 280). Natūraliai kyla klausimas, kodėl XXI a. organizacijoms ir jų lyderiams svarbu atkreipti dèmesị ị šiuos veiksnius? Vadybos moksle egzistuoja pozicija, kad organizacijos fizinè aplinka ir jos pokyčiai gali būti vertingas instrumentas, siekiant ịgyvendinti procesinius tarp darbuotojų vyks- 
tančius pokyčius, tobulinti komunikaciją ir darbinę elgseną, pabrèžiant tai, kad fizinè organizacijos aplinka neatsiejama nuo darbuotojų socialinių ryšių ir tarpusavio sąveikos, jai būdingi tam tikri kultūriniai kontekstai (pvz., tapatumas), ịvairios simbolistinès reikšmès (Danielsson, Bodin, 2008, p. 637; Tomi ir kt., 2015, p. 390-391). Vadinasi, svarbu nustatyti, kokie ịrodymai yra prieinami ir kokius pozityvius ar negatyvius argumentus galima būtų pateikti. Todèl fizinė aplinka šiame straipsnyje bus nagrinejjama pirmiausia iš tradicinès - uždaro biuro perspektyvos: apžvelgsime esminius tyrimus ir atskleisime galimą tokio biuro poveikị vadybiniams procesams, nagrinėdami tarpsektorinę ir tarptautinę organizacijų patirtį, tada dèmesi sutelksime ties atviro biuro galimu poveikiu ir specifika.

Nagrinèjant tradicinio - uždaro biuro erdvès ypatumus galima išskirti poziciją, kad fizinis atstumas ir fiziniai barjerai, kaip sienos ir darbuotojų išskirstymas skirtinguose aukštuose, gali būti vertinami kaip veiksnys, lemiantis labiau neigiamas tarpgrupinès sąveikos ir veiksmingo bendradarbiavimo pasekmes (Tomi ir kt., 2015, p. 391). N. M. Ashkanasy'io ir kt. (2014, p. 1173) teigimu, atvira fizinè erdvė gali sukurti tinkamas prielaidas darbuotojams stiprinti kolektyvinị tapatumą savo darbo vietoje dalijantis grupiniais apdovanojimais, sertifikatais, logotipais ir taip prisidedant prie grupinès darbo vizijos bei tapatumo stiprinimo.

Kita vertus, fiziniai aplinkos barjerai gali didinti darbuotojų hierarchinę diferenciaciją ir išryškinti vadovaujančio personalo statusą, taip pat jie gali prisidèti prie darbo efektyvumo didèjimo, nes atskiria darbuotojus nuo ịvairių išorinių stimulų, kaip pašalinis garsas, šviesa, todèl didejja darbinès veiklos privatumas. Uždaro biuro teikiamas privalumas yra ir darbuotojo privatumas, galintis užtikrinti, kad atliekant atsakingas funkcijas kiti kolegos nesutrukdys ar nenutrauks jo veiklos (Elsbach, Pratt, 2007, p. 191-192). V. Peteri's ir kt. (2020, p. 2-5) pritaria šioms ịžvalgoms ir teigia, kad uždaras biuras sietinas su industrinès eros organizacijomis, aiškia tvarka, hierarchiniu ir funkciniu pasiskirstymu. Ypač tai buvo pastebima analizuojant viešojo sektoriaus, biurokratinių organizacijų fizinę aplinką. S. Tuncer'is ir G. Licoppe (2018, p. 13) aptarè uždaros fizinès erdvės specifiką, jų teigimu, uždarytos durys gali suteikti darbuotojams saugumo, privatumo, kita vertus, dalinis jų užvėrimas gali rodyti darbuotojo prieinamumą kitiems, pvz., praviros durys gali simbolizuoti, kad darbuotojas laukia lankytojų, o visiškai atviros durys gali prisidèti prie efektyvesnių informacijos srautų judèjimo. Fizinių aplinkos barjerų kritiką galima sieti su darbuotojų tarpusavio sąveikos minimizavimu. Kuo arčiau vienas kito yra darbuotojai, tuo labiau dideja tikimybè, kad jie vienas kitą sutiks. Socialinę sąveiką gali skatinti ne tik biuro, bet net ir paties pastato dydis: kuo pastatas mažesnis, tuo galimai artimesni bus darbuotojų tarpusavio santykiai (Davis, 1984, p. 272-273), bet akivaizdu, kad intensyvesnè darbuotojų sąveika nenumato dažnų susitikimų pasekmių. Viena vertus, galima daryti prielaidą, 
kad tai skatins darbuotojus bendrauti, kita vertus, gali skatinti konfliktus, pasyviai agresyvius darbuotojų santykius, ịvairias psichologines frustracijas. J. Tomi'ui ir kt. (2015, p. 397) Suomijos laikraščio redakcijoje atlikus tyrimą pastebėta, kad darbuotojai daugiau bendradarbiavo su kolegomis, kurie fizinès aplinkos požiūriu buvo arčiausiai jų, o su tais, kuriuos nuo kolegų skyrė fiziniai apribojimai (sienos, kitas aukštas), informacija dalijosi mažiau. Visgi galima aptikti ir kitu nuomonių, pavyzdžiui, K. Elsbach'as ir M. G. Pratt'as (2007, p. 193) teigia, kad fizinès aplinkos barjerai gali gerinti neformalią komunikaciją, nes darbuotojai žinos, kad jų tarpusavio sąveika netrukdys kitiems kolegoms.

Analizuojant ịvairių mokslininkų atliktų tyrimų rezultatus galima teigti, kad svarbu pasirinkti tinkamą biuro fizinę struktūrą, atsižvelgiant ị organizacijos dydị, funkcijas, specifiką. Jeigu atliekamos veiklos specifika neatitiks biuro tipo, gali mažèti darbuotojų produktyvumas, jie gali kreiptis dèl galimybès dirbti namuose (Kaarlela-Tuomaala ir kt., 2009, p. 1426). Pažymėtina, kad vertinant darbuotoju biuro - fizinès aplinkos poveiki svarbi ir apšvietimo kokybè. J. A. Veitch'as ir kt. (2008, p. 145) atlikto tyrimo pagrindu diskutavo dèl to, kad apšvietimo gerinimas gali turèti įtakos darbuotojų biuro vertinimui: kuo kokybiškesnis apšvietimas, tuo pozityviau darbuotojai gali vertinti savo biuro fizinę aplinką, nepaisant jos uždarumo ar atvirumo.

Svarbu pabrèžti, kad tradicinis uždaras biuras gali lemti veiklos nuspėjamumo pojūtį, o biuro pokyčiai gali ir nepasiteisinti: lemti įvairias neigiamas darbuotojų produktyvumo pasekmes. Kaip atskleidè A. Brennan'o ir kt. (2002, p. 293) atliktas longitudinis tyrimas, biuro pokyčiai, pereinant nuo uždaro prie atviro, mažino darbuotojų pasitenkinimą darbu, didino psichologinị stresą ir neigiamai veikè komandos narių tarpusavio santykius. Šis tyrimas atskleide, kad biuro transformacijos nulemta adaptacija nebūtinai yra sẻkminga.

Apibendrinant galima teigti, kad organizacijos fizinè aplinka atlieka ịvairias socialines-kultūrines funkcijas. Esminiai pozityvūs uždaro biuro bruožai - privatumo užtikrinimas, darbuotojų atliekamų funkcijų ir hierarchinių formalių pozicijų atskyrimas, prieinamumo mažinimas.

\section{Atviro biuro įtaka tobulinant vadybos procesus, siekiant inovatyvumo}

Plètojant mokslinę diskusiją apie organizacijos fizinès erdvès svarbą, uždaro biuro trūkumus ir privalumus, natūraliai kyla klausimas, ar atviras biuras yra vadybinių procesų tobulinimo panacėja? Akivaizdu, kad ịrodymai tikrai nèra vienpusiški. Vertinant iš istorinès perspektyvos galima teigti, kad atviras biuras minimizuojant aplinkos barjerus ypač didelio dèmesio sulaukẻ 1970 metais. Biuro atvirumas sietas su organizacinių procesų lankstumu, gebèjimu geriau prisitaikyti 
prie vykstančių pokyčių, komunikacijos tarp grupių ir skyrių tobulinimu. Daugeliu atvejų fizinès aplinkos pokyčiai lèmė ir darbuotojų organizacinès kultūros transformacijas, tam tikrų nusistovejjusių tradicijų ir praktikų atsisakymą, pavyzdžiui, net pasisveikinimas ryte atejus ị darbą atvirame biure gali būti nebereikalingas, nes darbuotojai niekada nežino, kaip tai gali paveikti greta dirbančius kolegas, atliekančius atsakingas užduotis (Brennan ir kt., 2002, p. 280-281, Peteri ir kt., 2020, p. 10-11).

Šie pokyčiai gali skirtingai paveikti darbuotojus, tai priklauso nuo jų pareigų. K. Elsbach'as ir M. G. Pratt'as (2007, p. 192), remdamiesi J. R. Carlopio ir D. Gardner'io, M. D. Zalesny'io, R. V. Farace tyrimais, pateikia vertingų ižvalgų, akcentuodami, kad organizacinių barjerų mažinimas, biuro transformacija pereinant nuo uždaros prie atviros fizinès aplinkos gali mažinti aukštesnio lygmes darbuotojų pasitenkinimą darbu, bet didinti žemesnio lygmens darbuotojų pasitenkinimą darbu. Taigi galima teigti, kad siekiant fizinès aplinkos pokyčių, būtina ịvertinti galimą skirtingą jų poveikị darbuotojams, atsižvelgiant ị jų pareigas, socialinị statusą ir tenkančią atsakomybę. Akcentuotinas ir galimas tokių nusistovėjusių organizacinès kultūros elementų, kaip darbo apranga, pasikeitimas. Inovatyvios atviros biuro sąlygos kultūriniu požiūriu gali simbolizuoti laisvę ir neformalumą, tad biurokratinei organizacijai būdingas formalumas turètų keistis. Neformalių zonų kūrimas ir fizinès erdvès keitimas gali lemti demografinę darbuotojų sudèties kaitą. V. Peteri'io ir kt. (2020, p. 11) teigimu, neformaliose zonose išdèstant sẻdmaišius (angl. beanbags) svarbu turèti omenyje, kad norint jais naudotis reikia tam tikros fizinès būklès, jie gali būti naudojami jaunesnių darbuotojų, šie pasikeitimai savaime numato ir laisvesnę aprangą. Taigi galima daryti prielaidą, kad biuro atvirumui gali pasipriešinti vyresnių darbuotojų grupè. Iš kritinių argumentų galima paminèti ir akustikos pasikeitimą, asmeninès erdvès sumažejimą, sunkiai kontroliuojamą socialinę sąveiką (Kaarlela-Tuomaala ir kt., 2009, p. 1423). Galima pritarti N. M. Ashkanasy'io ir kt. (2014, p. 1172) nuomonei, kad atviro biuro zonos, kuriose darbuotojus skiria labai nedidelè erdvè, gali skatinti konfliktines situacijas, darbinès veiklos pertrūkius ir mažinti darbuotojų produktyvumą.

Tikètina, kad šiuos neigiamus veiksnius verslo organizacijos toleruoja. Tai galima mėginti aiškinti tuo, kad esminis verslo organizacijų funkcionavimo tikslas pelnas, o atvira fizinė organizacijos aplinka kainuoja mažiau. A. Brennan'as ir kt. (2002, p. 282) argumentuoja, kad daugelis bendroviu pereina prie atviros organizacijos fizinès erdvès, nes tai leidžia sumažinti finansines išlaidas, îrengiant ir išlaikant paskiras erdves.

Ankstesni tyrimai atskleidè, kad darbuotojai pasisako už galimybę pasirinkti, kokioje organizacijos aplinkoje jie norètų dirbti, kad galètų kontroliuoti fizinès aplinkos ypatybes, pavyzdžiui, biure tvyrantị triukšmą, esamą apšvietimą, oro tem- 
peratūrą ir kita (Samani ir kt., 2015, p. 94-103). Todèl atviruose biuruose dirbantiems asmenims svarbios tampa fizinès ir technologinès daugiakanalès bendradarbiavimo struktūros, skaitmeninè architektūra: elektorinis paštas, įmonių socialinè žiniasklaida ir komunikacija, mobilieji pranešimai, kita, siekiant išlaikyti darbo ir darbo aplinkos privatumą, susikaupimą, nepertraukiamumą. Pastebèta, kad organizacijoms darbą pradejjus organizuoti atvirų biurų principu, darbuotojų tiesioginis nenuotolinis bendravimas mažèja, o elektroninè sąveika didejja, siekiant kompensuoti tiesioginio nenuotolinio tarpusavio bendravimo trūkumą (Monaghan, Ayoko, 2019, 228-245). Taigi atviruose biuruose tarsi kuriama nematoma siena, kai darbuotojai netrukdomi ir darbai nepertraukiami gyvais pokalbiais: todèl aktyviau bendraujama skaitmeninejje erdveje, tai skatina organizacijas apmąstyti galimus fizinès aplinkos pokyčius organizuojant nuotolinị darbą.

Apibendrinant galima teigti, kad organizacijų vadybinių procesų pokyčiai ypač susiję su fizinės aplinkos pasikeitimu. Straipsnyje atlikta organizacijų fizinės aplinkos reikšmės tyrimų analizè atskleidè, kad organizacijos fizinè aplinka gali skatinti arba varžyti vadybinius procesus. Autoriai siūlo, kad organizacijos, igyvendindamos vadybinių procesų pokyčius, ịvertintų ir fizinès aplinkos reikšmę.

\section{Išvados}

Organizacijų fizinė aplinka ypač reikšminga, nes gali skatinti arba varžyti vadybinius procesus. Ji atlieka įvairias socialines-kultūrines funkcijas. Esminiais pozityviais uždaro biuro bruožais galima laikyti darbuotojų privatumo užtikrinimą, atliekamų funkcijų ir formalių hierarchinių pozicijų atskyrimą, prieinamumo mažinimą, socialinio statuso ir kontrolès formų įtvirtinimą.

Kaip uždaro organizacijos biuro neigiamus bruožus galima minèti ribojamą komunikaciją, neformalių santykių minimizavimą, kontrsubkultūrų formavimąsi ir komandinio darbo veiksmingumo ribojimą.

Atviro biuro fizinè erdvè gali stiprinti neformalią komunikaciją, didinti jos dažnị, prisidèti prie darbuotojų kūrybiškumo skatinimo ir organizacinès kultūros pokyčių, didinti darbuotojų tarpusavio priklausomybę ir stiprinti kolektyvinị tapatumą.

Perejjimas nuo uždaro prie atviro biuro fizinès erdvès gali lemti darbuotojų nepasitenkinimą, didesnị stresą, konfliktines situacijas, o socialinių kontaktų gausa gali turèti ịtakos konfliktinių situacijų dažniui.

Atviro biuro erdvėse darbuotojai mažiau gali kontroliuoti fizinę aplinką triukšmą, garsą, oro temperatūrą, tai didina jų nepasitenkinimą darbu bei darbo aplinka. 
Adomas Vincas Rakšnys, Deimantė Žilinskienė

Atviro biuro erdvėse gerokai išauga darbuotojų nuotolinė komunikacija skaitmeninėmis architektūromis: elektroniniais laiškais, pokalbių programėlèmis, siekiant nepertraukti atviroje erdvèje dirbančio asmens ir išvengti konfliktinių situacijų.

Organizacijos, ịgyvendindamos vadybinių procesų pokyčius, turètų ịvertinti ir fizinès aplinkos reikšmę, jos teikiamus privalumus ir trūkumus. Tarptautinių tyrimų analizė atskleidè, kad šiems procesams būtinos atitinkamos vadybinès kompetencijos.

\section{Literatūra}

Ashkanasy, N. M., Ayoko, O., Jehn, K. (2014). Understanding the physical environment of work and employee behavior: An affective events perspective Journal of Organizational Behavior. Journal of Organizational Behavior, Vol. 35, p. 1169-1184.

Brennan, A., Chugh. J. S., Kline, T. (2002). Traditionalversus Open Office Design a Longitudinal Field Study. Environment and Behavior, Vol. 34 (3), p. 279-299.

Davis, T. R. V. (1984). The Influence of the Physical Environment in Offices. The Academy of Management Review, Vol. 9 (2), p. 271-283.

Danielsson, Ch. B., Bodin, L. (2008). Office Type in Relation to Health, Well-Being, and Job Satisfaction Among Employees. Environment and Behavior, Vol. 40 (5), p. 636-668.

Elsbach, K., Pratt, M. G. (2007). The Physical Environment in Organizations. The Academy of Management Annals, p. 181-224.

Veitch, J. A., Newsham, G. R., Boyceb, P. R., Jones, C. C. (2008). Lighting appraisal, well-being and performance in open-plan offices: A linked mechanisms approach. Lighting Research And Technology, Vol. 40, p. $133-151$.

Kaarlela-Tuomaala, A., Helenius, R. E., Keskinen, E., Hongisto, V. (2009). Effects of acoustic environment on work in private office rooms and open-plan offices - longitudinal study during relocation. Ergonomics, Vol. 52 (11), p. 1423-1444.

Monaghan, N., Ayoko, O. B. (2019). Open-plan office, employees' enactment, interpretations and reactions to territoriality. International Journal of Manpower, Vol. 40 (2), p. 228-245.

Peteri, V., Lempiäinen, K., Kinnunen, M. (2020). From cubicles to open space: An analysis of gendered meanings of workspace. European Journal of Cultural Studies, p. 1-18.

Samani, S. A., Rasid, S. Z., Sofian, S. (2015). Individual control over the physical work environment to affect creativity. Industrial Engineering and Management Systems, Vol. 14 (1), p. 94-103.

Sylvaine, T., Licoppe, Ch. (2018). Open door environments as interactional resources to initiate unscheduled encounters in office organizations. Culture and Organization, Vol. 24 (1), p. 11-30.

Tomi, J., Kallio, K. M., Kallio, A., Blomberg, J. (2015). Physical space, culture and organisational creativity - a longitudinal study. Facilities, Vol. 33 (5), p. 389-411.

\section{THE IMPORTANCE OF AN ORGANISATION'S PHYSICAL ENVIRONMENT IN MANAGEMENT PROCESSES}

\section{Adomas Vincas Rakšnys, Deimantė Žilinskienė}

\section{Summary}

The constantly changing specifics of the activities of modern business and public and non-governmental organisations include the complexity of tasks and pro- 
blems to be solved, the change in procedures, and the need to look for new ways to increase the efficiency of employees. Employees increasingly have to have wideranging competencies, and be able to work in conditions of globalisation and a high-risk and knowledge economy, use modern technologies, and apply different methods and the best international management principles and practices in their activities. However, various requirements are placed not only on employees, but also on organisations, such as a competitive environment, good global practices, and the application of the juxtaposition method to encourage organisations to invest primarily in the improvement of the physical environment of the organisation. This trend is also observed in the context of Lithuanian organisations, especially in the business sector. In the scientific discourse, there are various pieces of research examining the connection between the physical environment of the organisation and various aspects of employee activity, and their possible influence on the efficiency of employee activity. The possible impact of the physical environment, especially informal spaces (smoking and coffee drinking spaces), on the formation of organisational subcultures, which can challenge the dominant organisational hierarchy and the organisational culture, is discussed. J. Tomi et. al. conducted a study in Finland which observed changes in the organisational culture and employee creativity factors as the physical environment of the organisation changed, moving from a more bureaucratic closed environment to a more open office editorial office. J.A. Veitch et. al. showed that the quality of lighting used in offices increases employee productivity, and improves employees' psychological condition. Evaluating conclusions formed on the basis of this and other research, it can be assumed that the physical environment of the organisation can have various functions that promote and restrict the internal processes of the organisation; therefore, the formation of a suitable environment is a prerequisite for employee efficiency. V. Peteri et. al. (2020, p. 2) argue that the manipulation of an organisation's physical space can also create new forms of governance, change existing power relations, establish forms of control, and even unite employees.

Nevertheless, the research into these complex factors requires primarily an interdisciplinary methodological approach, combining a knowledge of management, economics, psychology, architecture, and other fields, and this topic does not receive sufficient attention in the Lithuanian scientific discourse. The article raises a scientific problem: what is the possible impact of the physical environment on processes taking place in organisations? The aim is to find out the essential possible stimulating and restrictive effects of the physical environment on the procedures of organisations. To achieve this goal, the authors use methods of analysis, meta-analysis, systematic analysis, synthesis, generalisation, and comparison of scientific literature. 
Adomas Vincas Rakšnys, Deimantė Žilinskienè

Adomas Vincas Rakšnys - docentas, daktaras (socialiniai mokslai - vadyba). Kazimiero Simonavičiaus universiteto Verslo mokykla ir Vilniaus kolegijos Verslo vadybos fakulteto Verslo inovacijų katedra.

El.paštas: e_cnv@yahoo.com 